Journal Knowledge Industrial Engineering (JKIE)

\title{
PEMANFAATAN E-COMMERCE BUSINESS TO CONSUMER (B2C) MARKETPLACE UNTUK PENGEMBANGAN USAHA MIKRO,KECIL DAN MENENGAH (UMKM)
}

\author{
Prasetyo Dono Saputro \\ Prodi Teknik Industri - Fakultas Teknik - ITSNU Pasuruan \\ Email koresponden : Prasetyo@yahoo.com
}

\begin{abstract}
Abstrak
Dalam menyongsong Revolusi Industri 4.0 ditandai era ekonomi digital (Digital Economy Era).Era ekonomi baru ditandai dengan penerapan teknologi informasi dalam menjalankan kegiatan ekonominya. Pengguna internet di Indonesia usia 13-18 tahun =16,68\%,usia 19-34 tahun $=49,52 \%$, usia 35-54 tahun $=29,55 \%$,usia $>54$ tahun $=4,24 \%$. Dan jumlah pengguna internet berdasarkan jenis kelamin, jenis kelamin pria sebesar $=51,43 \%$, jenis kelamin perempuan sebesar $=48,57 \%$. Penggunaan internet saat ini bahkan telah merambah ke sistem e-commerce market place yang merupakan kegiatan jual beli barang/jasa melalui jaringan elektronik (internet). Transaksi melalui e-commerce melibatkan 3 pihak, yaitu : suppliers/partners, pengelola website (our company), dan pelanggan (customer). Adapun data pemanfaatan internet sebagai berikut : mencari harga $=45,12 \%$, membantu pekerjaan = $41,04 \%$, informasi membeli $=37,82 \%$, beli online $=32,19 \%$, cari kerja $=26,19 \%$, transaksi perbankan $=17,04 \%$, jual online $=16,83 \%$. Tahapan yang terjadi pada e-commerce market place adalah: (1) Pemesanan dilakukan secara online (dilakukan oleh pembeli); (2) Melakukan konfirmasi pembayaran (dilakukan oleh pembeli); (3) Memeriksa kondisi stock barang (dilakukan oleh penjual);(4) Melakukan pengaturan pengiriman barang (mengatur jasa pengiriman yang disediakan oleh sistem e-commerce marketplace, biasanya dilakukan oleh penjual);(5) Retur (proses garansi biasanya dilakukan dalam sistem e-commerce market place, tujuannya agar kepercayaan pelanggan dapat tercapai / terpenuhi)
\end{abstract}

Kata kunci : e-commerce, market place, UMKM

\begin{abstract}
In welcoming the Industrial Revolution 4.0 marked the era of the digital economy (Digital Economy Era). The new economic era is characterized by the application of information technology in carrying out its economic activities. Internet users in Indonesia aged 13-18 years $=16.68 \%$, age $19-34$ years $=49.52 \%$, age $35-54$ years $=29.55 \%$, age $>54$ years $=4.24 \%$. And the number of internet users by sex, male gender is $=51.43 \%$, female gender is $=48.57 \%$. The use of the internet today has even penetrated into the e-commerce market place system which is a sale and purchase of goods / services through electronic networks (internet). Transactions through e-commerce involve 3 parties, namely: suppliers / partners, website managers (our company), and customers (customers). The data on internet usage are as follows: looking for prices = $45.12 \%$, helping jobs $=41.04 \%$, buying information $=37.82 \%$, buying online $=32.19 \%$, looking for work $=26.19 \%$, banking transactions $=17.04 \%$, selling online $=16.83 \%$. The stages that occur in e-commerce market place are: (1) Orders are made online (carried out by the buyer); (2) Confirming payment (carried out by the buyer); (3) Checking the condition of the stock of goods (carried out by the seller); (4) Arranging the delivery of goods (arranging shipping services provided by the e-commerce marketplace system, usually carried out by the seller); $e$ commerce market place, the goal is that customer trust can be achieved / fulfilled)
\end{abstract}

Keywords: e-commerce, market place, MSME (Micro, Small, Medium Enterprises)

\section{PENDAHULUAN}

Usaha kecil dan menengah (UKM) memiliki peranan yang sangat penting dalam pertumbuhan ekonomi dan industri.Menyadari pentingnya peranan UKM dalam perekonomian 
negara ini, sudah selayaknya bila mendapatkan perhatian dari pemerintah untuk mendorong kemandirian dan keberhasilan pelaku usaha.

Dalam menyongsong Revolusi Industri 4.0 ditandai era ekonomi digital (Digital Economy Era).Era ekonomi baru ditandai dengan penerapan teknologi informasi dalam menjalankan kegiatan ekonominya.

Jumlah Pembeli "Online" Indonesia capai 11,9 persen dari populasi. Jual beli secara online yang didorong oleh pertumbuhan industri e-commerce market place di Tanah Air turut meningkatkan jumlah pembeli melalui platform tersebut (ekonomi kompas.com, 2018).

Penerapan teknologi informasi yang dibutuhkan pada Revolusi Industri 4.0 untuk pengembangan UKM adalah berbasis web dan aplikasi. Banyak sistem e-commerce yang berbasis marketplace yang memudahkan UKM untuk berkembang.Apalagi sistem e-commerce marketplace tersebut sangat gencar untuk membantu UKM dalam mengembangkan usaha dalam jual beli online.

Pangsa pasar e-commerce Indonesia pada 2015 mencapai US\$ 1,68 miliar atau baru sekitar 1,2 persen dari penjualan ritel senilai US\$ 145,83 miliar. Penjualan e-commerce Indonesia diperkirakan akan mencapai US\$ 46 miliar atau sekitar 8 persen dari penjualan ritel pada 2025 (databoks.katadata.co.id,2017).

\section{INFOGRAFIS HASIL SURVEY 2017}
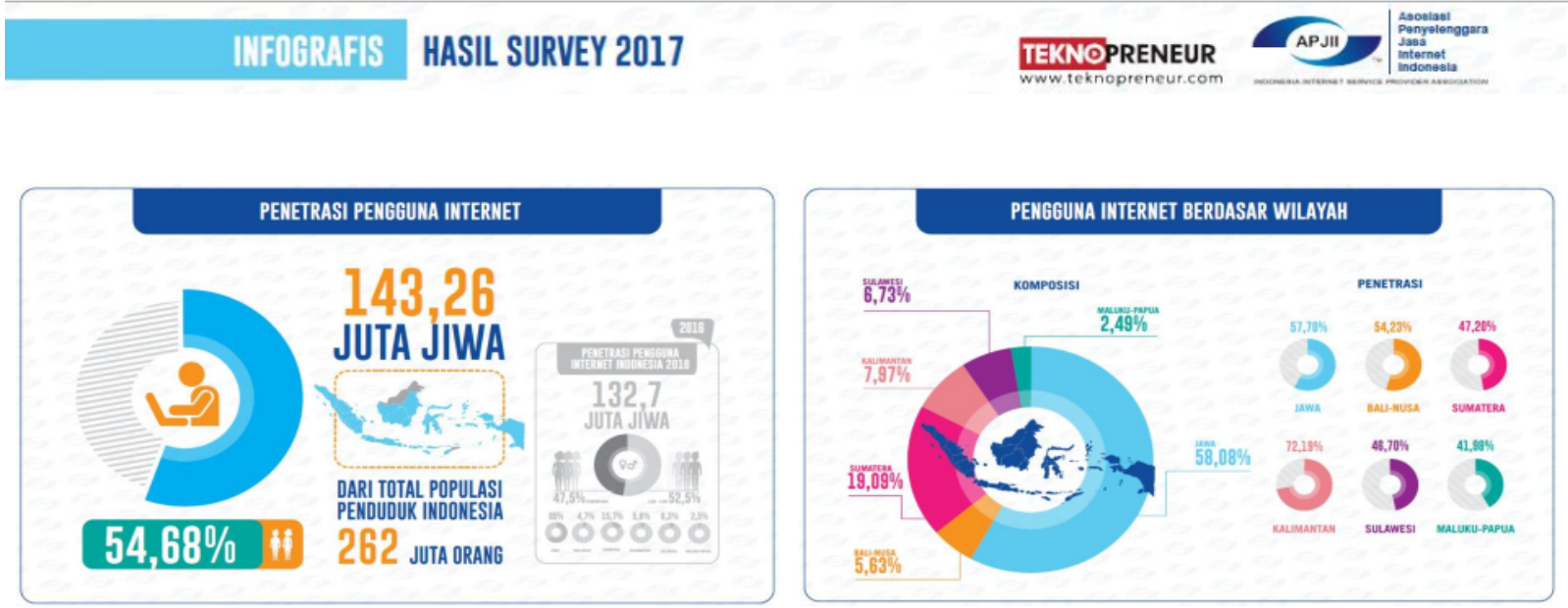

Gambar 1 : Survei penetrasi pengguna internet berdasarkan jumlah dan berdasarkan wilayah

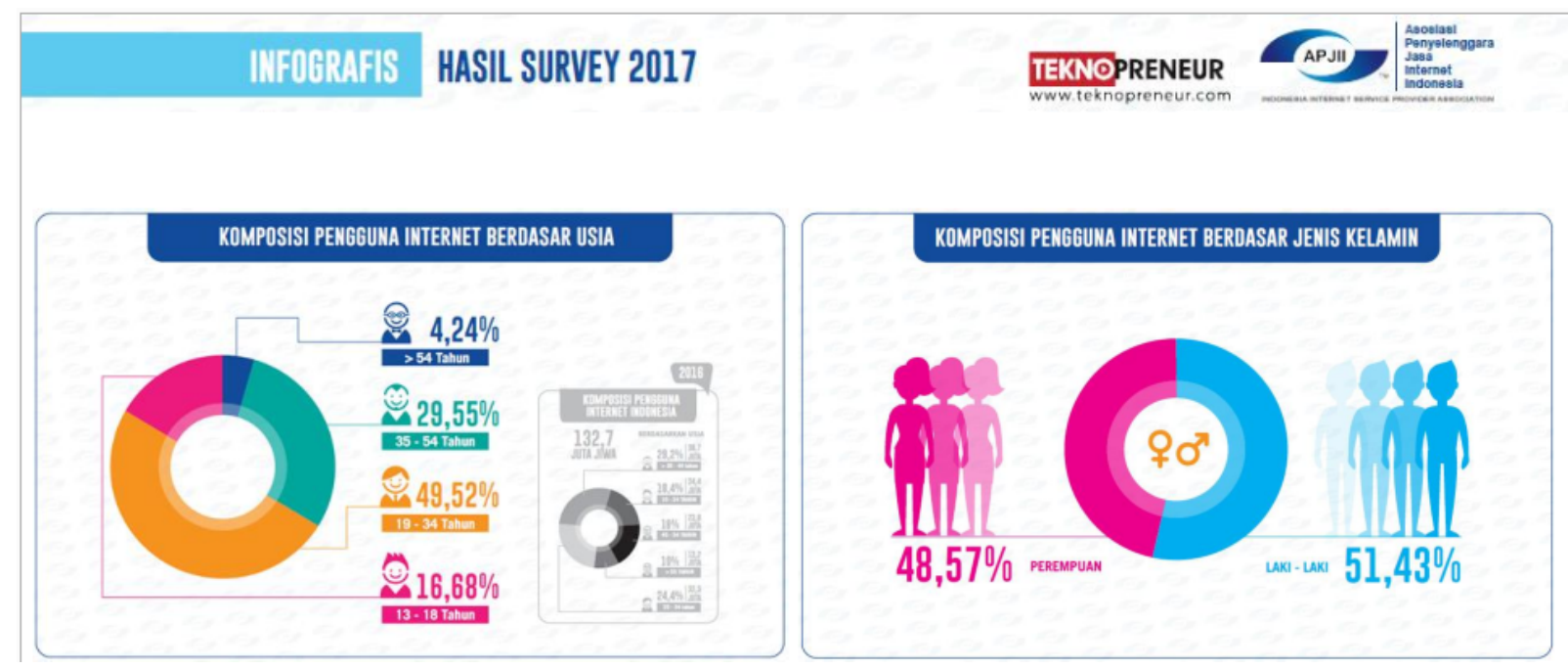

Gambar : 2 Komposisi pengguna internet berdasarkan usia dan jenis kelamin

Berdasarkan gambar 2 diketahui bahwa internet telah menjamah berbagai usia termasuk usia remaja (13-18 tahun), bahkan usia lansia (> 54 tahun). Dari gambar 2 dapat diketahui bahwa 
pengguna internet usia 13-18 tahun : 16,68\%,usia 19-34 tahun : 49,52 \%, usia 35-54 tahun : 29,55 $\%$, >54 tahun : 4,24\%. Dan jumlah pengguna internet berdasarkan jenis kelamin, jenis kelamin pria sebesar: 51,43 \%, jenis kelamin perempuan sebesar: 48,57\%. Penggunaan internet saat ini bahkan telah merambah ke sistem e-commerce market place yang merupakan kegiatan jual beli barang/jasa melalui jaringan elektronik (internet).Menurut Turban (2010, hal 199), mendefinisikan sebagai berikut Electronic Commerce (EC or e-commerce) describes the process of buying, selling, transferring, serving, or exchanging products, services, or information via computer networking including the Internet.

Tabel : 1 Perbandingan kegiatan usaha antara era ekonomi lama dengan era ekonomi baru (revolusi industri 4.0)

\begin{tabular}{|c|l|l|l|}
\hline No. & \multicolumn{1}{|c|}{ Jenis Kegiatan } & \multicolumn{1}{|c|}{ Era Ekonomi Lama } & \multicolumn{1}{|c|}{ Era Ekonomi Baru } \\
\hline 1 & Pembelian & $\begin{array}{l}\text { Calon pembeli datang ke } \\
\text { took }\end{array}$ & $\begin{array}{l}\text { Calon pembeli mengun- } \\
\text { jungi website }\end{array}$ \\
\hline 2 & Pemesanan barang & $\begin{array}{l}\text { Melakukan pemesanan di } \\
\text { took }\end{array}$ & $\begin{array}{l}\text { Melakukan pemesanan me- } \\
\text { lalui fitur yang disediakan } \\
\text { website/ aplikasi }\end{array}$ \\
\hline 3 & Kegiatan pemasaran & $\begin{array}{l}\text { Melalui brosur, spanduk, } \\
\text { leaflet, banner, dari mulut } \\
\text { ke mulut }\end{array}$ & $\begin{array}{l}\text { Melalui situs jejaring sosial, } \\
\text { search engine, situs iklan } \\
\text { online }\end{array}$ \\
\hline 4 & Penyediaan sarana fisik & $\begin{array}{l}\text { Harus menyediakan took } \\
\text { untuk display barang }\end{array}$ & $\begin{array}{l}\text { Tidak harus menyediakan, } \\
\text { karena sudah memanfaat- } \\
\text { kan katalog produk secara } \\
\text { digital }\end{array}$ \\
\hline 5 & Biaya pemasaran & $\begin{array}{l}\text { Cukup besar, karena harus } \\
\text { mencetak brosur, spanduk, } \\
\text { leaflet, banner. }\end{array}$ & $\begin{array}{l}\text { Tidak besar. Dengan me- } \\
\text { manfaatkan status jejaring } \\
\text { sosial, bisa melakukan ke- } \\
\text { giatan pemasaran. }\end{array}$ \\
\hline 6 & Jangkauan konsumen & $\begin{array}{l}\text { Lebih sempit, karena ter- } \\
\text { batas di lingkungan took } \\
\text { tersebut berada. }\end{array}$ & $\begin{array}{l}\text { Lebih luas, karena jang- } \\
\text { kauan internet yang dapat } \\
\text { menjangkau dunia lebih } \\
\text { luas (global) }\end{array}$ \\
\hline
\end{tabular}

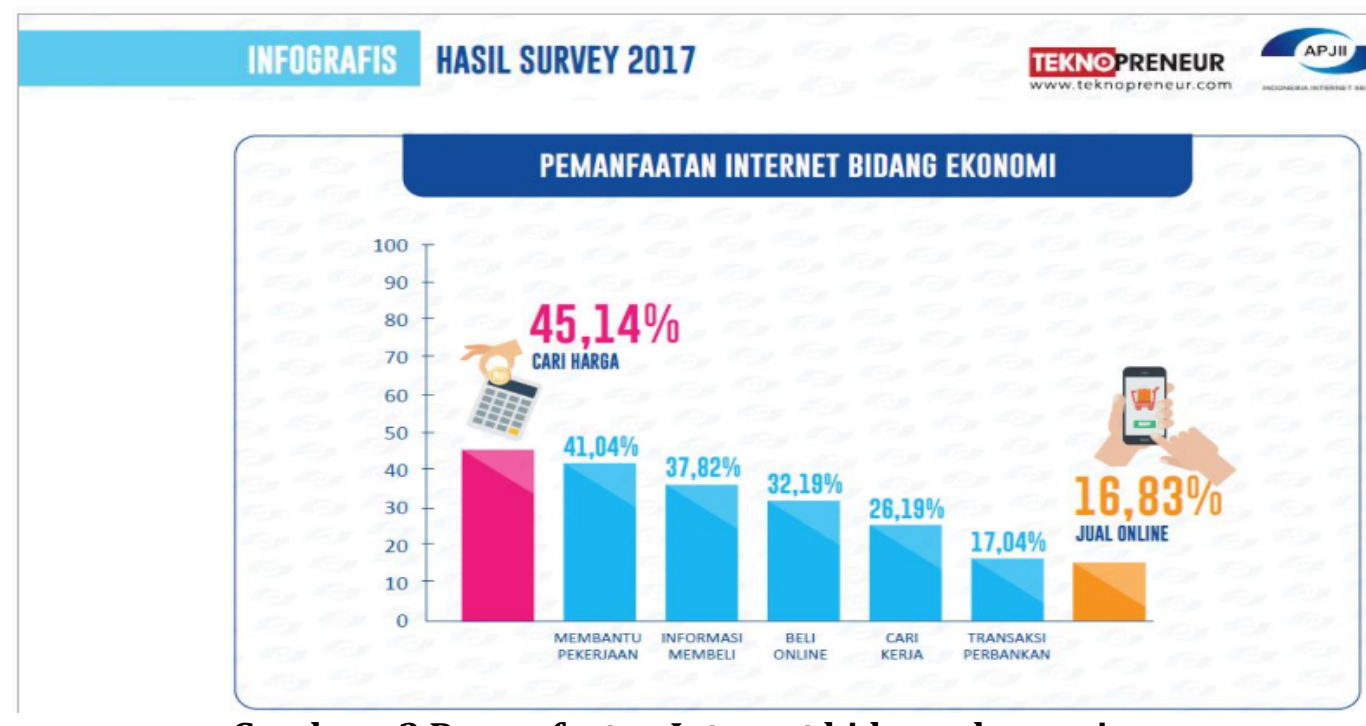

Gambar : 3 Pemanfaatan Internet bidang ekonomi

Dari gambar 3 dapat diketahui prosentase jual beli online dalam pemanfaatan internet di bidang ekonomi. Adapun data pemanfaatan internet sebagai berikut : mencari harga : 45,12\%, 
membantu pekerjaan : 41,04\%, informasi membeli : 37,82 \%, beli online : 32,19\%, cari kerja : 26,19 $\%$, transaksi perbankan : 17,04\%, jual online : $16,83 \%$.

Menurut Kuncoro (2000), tantangan yang dihadapi oleh pengusaha kecil dapat dibagi menjadi dua kategori. Kategori pertama adalah pengusaha kecil dengan omset kurang dari Rp 50.000.000,- dan tantangan dari kategori pertama adalah bagaimana menjaga kelangsungan hidup usahanya. Kategori kedua adalah pengusaha kecil dengan omset usaha antara Rp 50.000.000,hingga Rp 1.000.000.000,- dan tantangan yang dihadapi adalah : (1) belum mempunyai sistem administrasi keuangan dan manajemen yang baik, (2) masalah penyusunan proposal agar dapat memperoleh pinjaman dari bank, (3) masalah menyusun perencanaan bisnis, (4) masalah akses terhadap teknologi, (5) masalah memperoleh bahan baku, (6) masalah perbaikan kualitas barang dan efisiensi, (7) masalah tenaga kerja yang terampil.

Tujuan untuk penulisan artikel ini adalah untuk mendukung tercapainya kemudahan, efisiensi, efektivitas dalam melakukan transaksi bisnis dan penyediaan informasi yang akurat, tepat waktu dan relevan.Tujuan khusus adalah mengoptimalkan dalam pemanfaatan penggunaan $e$ commerce marketplace untuk pengembangan usaha kecil dan menengah.

\section{METODE PENELITIAN}

Metode penelitian yang digunakan adalah dengan conceptual framework dan empiris berdasarkan kajian literature yang berhubungan dengan teknologi informasi, usaha kecil dan menengah, e-commerce market place.

\section{Adopsi Teknologi}

Adopsi teknologi adalah proses multi dimensi, dimana mempunyai perilaku yang dipengaruhi oleh berbagai rangkaian keadaan (Dhewanto, Wawan, et al: 169).

\section{Usaha Mikro, Kecil dan Menengah (UMKM)}

Sesuai dengan Undang-undang Nomor 20 Tahun 2008 tentang Usaha Mikro, Kecil dan menengah (UMKM), dapat diartikan sebagai berikut :

a. Usaha Mikro adalah usaha produktif milik orang atau perseorangan dan atau badan usaha perorangan.

b. Usaha Kecil adalah usaha ekonomi produktif yang berdiri sendiri, dilakukan orang perorangan bukan merupakan anak perusahaan, bukan cabang perusahaan yang dimiliki, dan bukan menjadi bagian langsung atau tidak langsung dari usaha menengah atau usaha besar.

c. Usaha Menengah adalah usaha ekonomi produktif yang berdiri sendiri, dilakukan orang perorangan dan bukan merupakan anak perusahaan, bukan cabang perusahaan yang dimiliki, dan bukan menjadi bagian langsung atau tidak langsung dari usaha kecil atau usaha besar.

Dalam undang-undang nomor 20 tahun 2008 tentang Usaha Mikro, Kecil dan Menengah (UMKM), dapat digolongkan sesuai kriteria sebagai berikut :

a. Usaha Mikro mempunyai :

- Asset :maximum 50 juta

- Omzet : maximum 300 juta

b. Usaha Kecil mempunyai :

- Asset : $>50$ juta -500 juta

- Omzet :> 300 juta $-2,5 \mathrm{M}$

c. Usaha Menengah mempunyai :

- Asset :> 500 JUTA $-10 \mathrm{M}$

- Omzet : > 2,5 M - $50 \mathrm{M}$

Batasan Usaha Mikro, Kecil dan Menengah menurut Bank Indonesia, yaitu :

a. Usaha Mikro adalah usaha yang dijalankan oleh rakyat miskin atau mendekati miskin. Usaha tersebut dimiliki oleh keluarga dengan sumber daya lokal milik keluarga tersebut dan tidak memperoleh dari lembaga keuangan tertentu dan teknologi sederhana.

b. Usaha Kecil adalah usaha ekonomi produktif yang berdiri sendiri, yang dilakukan oleh perorangan atau badan usaha yang bukan merupakan anak usaha atau cabang perusahaan yang dimiliki, dikuasai, atau menjadi bagian baik langsung maupun tidak langsung dari 
usaha menengah atau usaha besar yang memiliki kekayaan bersih lebih dari Rp $50.000 .000,00$ (lima puluh juta rupiah) sampai dengan paling banyak Rp 500.000.000,00 (lima ratus juta rupiah) tidak termasuk bangunan dan tanah tempat usaha atau memiliki hasil penjualan tahunan lebih dari Rp 300.000.000,00 (tiga ratus juta rupiah) sampai paling banyak Rp 2.500.000.000,00 (dua milyar lima ratus juta rupiah).

c. Usaha Menengah adalah omset tahunan kurang dari 3 milyar dan asset sebesar 5 milyar untuk sektor industri, asset sebesar 600 juta di luar tanah dan bangunan untuk sektor non industri manufaktur (Dhewanto, Wawan, et al., 2015:23-24).

\section{E-commerce Market Place}

Menurut Mike Simpson dan Anthony J. Dochery (2004), e-commerce adalah sarana perdagangan yang melibatkan pengguna elektronik, terutama melalui internet, untuk proses jual dan beli, termasuk iklan, undangan, negosiasi dan hasil kontrak dan prestasi. Sedangkan $e$ commerce menurut Laudon dan Traver (2012:49) adalah penggunaan internet dan web untuk bertransaksi bisnis, memungkinkan terjadinya transaksi komersial antara organisasi dan individu.

E-commerce sebagai proses membeli dan menjual produk atau jasa dengan menggunakan data elektronik transmisi melalui internet dan www (Grandona dan Pearson dalam Peixin Li dan Wei Xie, 2012). Menurut Gouzali Saydam (2005) e-commerce adalah pertukaran barang, jasa dan atau informasi melalui medium elektronik dengan imbalan uang.Berdasarkan mediumnya e-commerce dibagi menjadi 2 e-commerce non internet dan $e$ commerce internet.

Menurut Boris Wertz dan Angela Tran Kingyens (2013), marketplace didefinisikan sebagai berikut; "Sebuah online marketplace (pasar online) adalah jenis dari situs e-commerce yang menghubungkan bagi mereka para penyedia produk atau jasa (penjual) dengan mereka yang mencari untuk membeli produk atau layanan (pembeli). Pembeli dan penjual ini mungkin memiliki kesulitan menemukan satu sama lain sebelumnya, dan dengan demikian online marketplace (pasar online) menciptakan efisiensi di pasar lainnya (offline) yang dianggap tidak efisien."

Menurut ditjenpdt.kemendesa.go.id e-commerce market place terdiri dari : (1) Business to business (B2B) : transaksi komersial antar pelaku bisnis, (2) Consumer to consumer (C2C) : transaksi komersial antar pribadi, (3) Business to consumer (B2C) : pasar yang mempertemukan antara penjual dan pembeli.

\section{Faktor-faktor yang mempengaruhi $e$-commerce}

Berikut faktor-faktor yang mendorong adopsi e-commerce yang diambil dari beberapa jurnal yaitu :

1. Perspektif Lingkungan

a. Lingkungan Institusi

Lingkungan institusi termasuk efisiensi sistem hukum, dan kebijakan pemerintah proaktif, mempengruhi keputusan banyak perusahaan.Dalam sebuah penelitian yang dilakukan oleh Price Waterhouse Coopers pada usaha kecil dan menengah (UKM) di daerah dalam Asia Pasific Economic Cooperation (APEC) dan menemukan bahwa kebijakan pemerintah adalah penentu yang sangat penting dari penerapan e-commerce.

b. Lingkungan Ekonomi

Dilihat dari tingkat perkembangan ekonomi suatu bangsa, infrastruktur IT di negara-negara berkembang sering tidak cukup berkembang untuk memainkan supply-dorongan peran dibandingkan dengan negara lain yang berkembang.

c. Lingkungan Sosiokultural

Kebudayaan nasional menentukan tidak hanya apakah entitas sosial di negara tertentu akan mengadopsi teknologi tertentu, tetapi juga sejauh mana inovasi teknologi diterima dan cara-cara yang digunakan.

2. Perspektif Perusahaan

a. Ukuran dan Struktur Perusahaan 
Adopsi e-commerce dipengaruhi oleh ukuran perusahaan dalam dua cara. Perusahaan besar sering memiliki bisnis, manusia, dan teknologi sumber daya yang cukup untuk berinvestasi dalam e-commerce.

b. Strategi Perusahaan

Diambil dari Berthon, strategi perusahaan secara keseluruhan dapat dibagi menjadi dua kategori, yakni orientasi inovasi dan orientasi konsumen. Perusahaan yang mengambil strategi inovasi selalu mencoba untuk mengeksplorasi kebutuhan laten saat ini dari konsumen, sedangkan perusahaan dengan orientasi konsumen lebih mengutamakan kebutuhan konsumen.

c. Globalisasi

Perusahaan menghadapi persaingan asing berada di bawah tekanan yang lebih besar untuk mengadopsi e-commerce guna memperluas pangsa pasar dan beroperasi secara lebih efisien.

d. Sikap Manajerial

Beberapa studi empiris menyelidiki peran sikap manajerial dalam adopsi $e$ commerce.Namun, manajemen memang memainkan peran penting dalam pengambilan keputusan.

e. Tekanan Eksternal (Konsumen dan Supplier)

Beberapa peneliti telah mempelajari perilaku perusahaan yang mengadopsi $e$ commercedari pandangan tekanan konsumen.

3. Perspektif Teknologi

a. Lingkungan Teknologi Makro

Infrastruktur IT dan internet yang memadai pada suatu negara dapat menjadi kunci faktor yang mempengaruhi adopsi e-commerce perusahaan.

b. Kekuatan Teknis Perusahaan

Kekuatan teknis perusahaan terwujud dengan kapasitas dalam mencerna dan menyerap teknologi baru yang mengatakan, apakah mereka dapat mengintegrasikan teknologi $e$ commerce dengan sistem informasi yang ada.

c. Manfaat

Konteks teknologi mengacu pada aspek-aspek seperti manfaat yang dirasakan, kompabilitas, dan biaya yang mempengaruhi adopsi teknologi e-commerce.Manfaat yang dirasakan mengacu pada tingkat penerimaan dari kemungkinan keuntungan yang diberikan oleh teknologi e-commerce untuk organisasi tersebut.

4. Adopsi IT

UKM harus mengadopsi IT untuk mengoptimalkan proses bisnis seperti perencanaan, pengendalian, kolaborasi dan komunikasi, kebutuhan informasi dan operasi internal dan espektasi, membuat keptusan waktu dan informasi, dan mengimplementasikan strategi bisnis.

5. Dukungan Pemerintah

Survey yang dilalukan oleh Zhang (2014) pada 114 UKM di Cina yang berpartisipasi dalam $\mathrm{B} 2 \mathrm{~B}$ e-commerce marketplace, menemukan bahwa pemerintah memainkan peran yang penting dalam menciptakan lingkungan e-commerce yang mendukung dan konsisten.Mereka merekomendasikan bahwa pemerintah harus memfasilitasi dan membantu penyediaan informasi untuk pengembangan adopsi e-commerce di tingkat internasional.

6. Perspektif Individu

- Kemampuan ITdan Pengalaman IT

Kemampuan IT dan pengalaman IT pemilik e-commerce juga diidentifikasi sebagai faktor penentu adopsi e-commerce oleh UKM di negara-negara berkembang.Secara umum, tidak cukup satu masalah yang sering muncul di UKM tentang kemampuan ITnya. Jika pemilik UKM memiliki kemampuan dan pengalaman IT yang lebih besar maka mereka akan percaya diri dalam mengadopsi IT dan akan mengurangi ketidakpastiandan resiko adopsi teknologi. Selain itu pula, pemilik UKM akan percaya 
bahwa keterampilan dan pengetahuan yang dimilikinya dapat membantu dan meningkatkan kecepatan adopsi teknologi itu sendiri.

\section{HASIL DAN PEMBAHASAN \\ Rancangan Aplikasi}

Transaksi melalui e-commerce melibatkan 3 pihak, yaitu :suppliers/ partners, pengelola website (our company), dan pelanggan (customer).

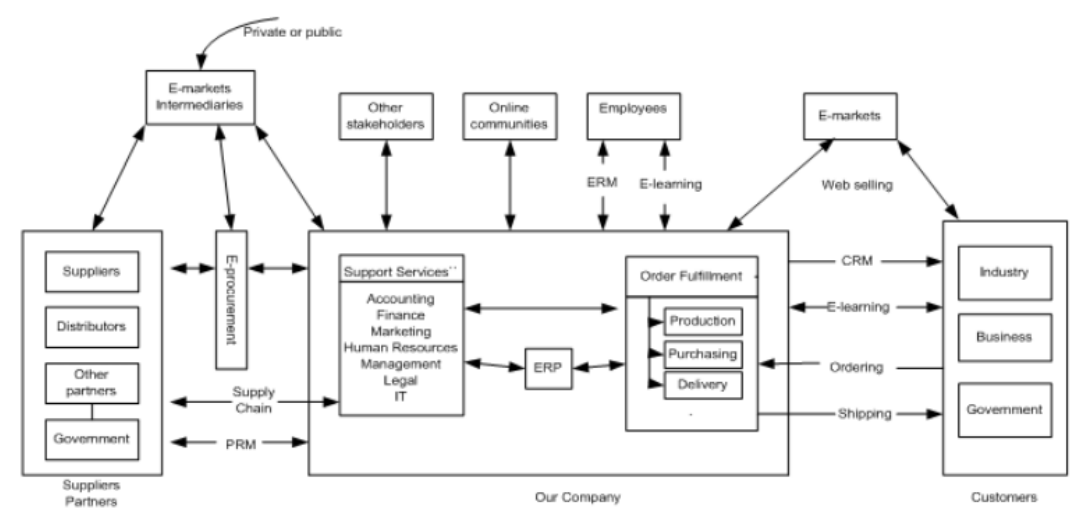

Gambar : 4 Rancangan aplikasi e-commerce (Turban, 2010)

Konsep dasar dari e-commerce market place adalah melakukan proses otomatisasi dari setiap proses yang ada di perusahaan, yaitu : proses pesan barang, proses pengadaan barang, proses pengiriman pesanan kepada pelanggan dan memberikan pelayanan terbaik kepada pelanggan dengan membuat Customer Relationship Management (CRM).

Dalam menghadapi mekanisme pasar adalam rangka revolusi industri 4.0, penguasaan pasar/market merupakan syarat utama untuk meningkatkan daya saing UMKM. Informasi pasar produksi (komoditas) yang diperlukan, contohnya : (1) jenis barang atau produk yang dibutuhkan oleh konsumen di daerah tertentu; (2) daya beli masyarakat terhadap produk tersebut; (3) harga ketentuan dari pasar; (4) selera konsumen pada pasar lokal, regional ataupun internasional.

Menurut Ishak (2005) bahwa informasi pasar merupakan faktor utama dari sebuah produksi dan untuk mengetahui : (1) sumber bahan baku yang akan dibutuhkan; (2) harga bahan baku yang akan dibeli; (3) bagaimana cara untuk memperoleh modal usaha; (4) dimana mendapatkan tenaga kerja yang professional; (5) tingkat upah atau gaji yang layak untuk karyawan; (6) dimana dapat memperoleh alat-alat atau mesin yang dibutuhkan.

Menurut Suyanto (2005) hal positif yang dapat didapat bila menggunakan dan memanfaatkan jaringan internet : (1) dapat mempertinggi promosi produk dan layanan melalui kontak langsung, kaya informasi, dan interaktif dengan pelanggan; (2) menciptakan satu saluran distribusi bagi produk yang ada; (3) biaya pengiriman informasi ke pelanggan lebih hemat jika dibandingkan jasa paket; (4) waktu yang dibutuhkan untuk menerima atau mengirim informasi sangat singkat.

Konten dari e-commerce market place juga harus di persiapkan dengan lengkap, agar pelayanan dan pemenuhan terhadap konsumen/pelanggan. Hal tentang konten tersebut antara lain : e-infrastructure ( berisi tentang system yang mengintegrasikan tentang website, hosting, keamanan jaringan, network), e-proses (berisi tentang cara pembayaran (cash/kredit), dan pengiriman (logistic)),e-market (berisi tentang pemasaran dan iklan), e-communities (berisi tentang komunitas, audience, partner bisnis), e-service(berisi tentang Customer Relationship Management, Partnership Relationship Management), e-content (berisi tentang sistem pendukung dari operator) 


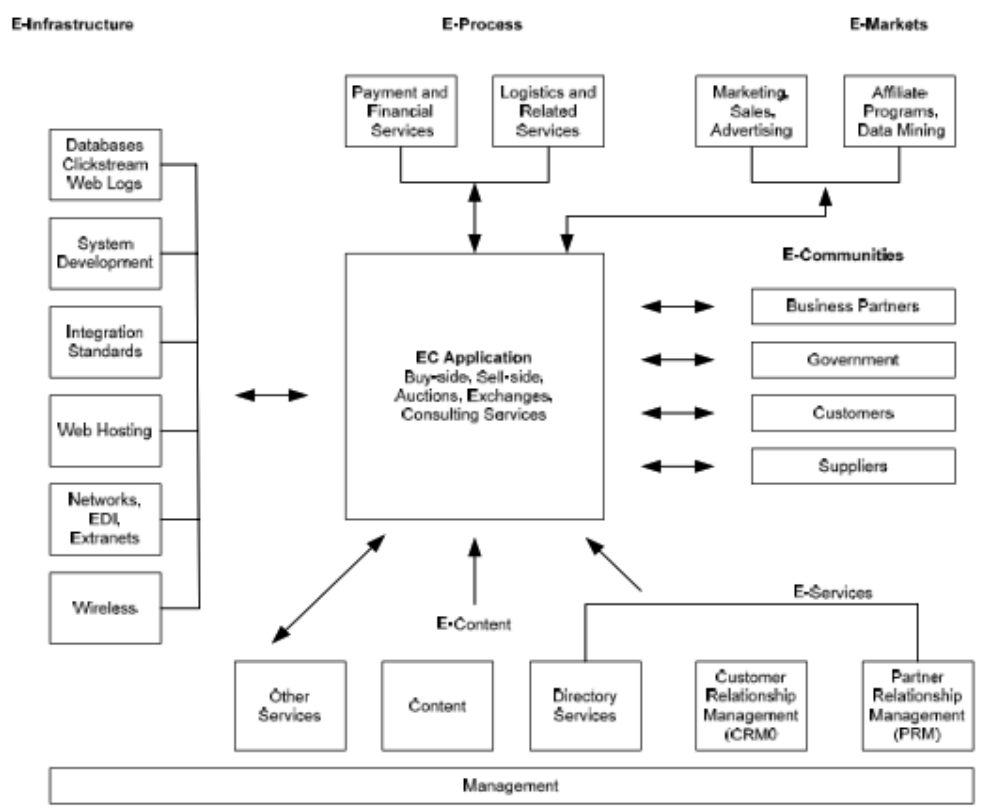

Gambar 5 : Komponen yang mendukung dari e-commerce (Turban, 2010)

Model transaksi e-commerce Business to Consumer (B2C), dalam transaksi ini, penjual adalah organisasi, sedangkan pembeli adalah individu. Business to Consumer (B2C) biasanya juga dikenal sebagai e-tailing (electronic retailing).

\section{KESIMPULAN}

Dapat disimpulkan sebagai berikut :

1. Tahapan yang terjadi pada e-commerce market place adalah:

a. Pemesanan dilakukan secara online (dilakukan oleh pembeli)

b. Melakukan konfirmasi pembayaran (dilakukan oleh pembeli)

c. Memeriksa kondisi stock barang (dilakukan oleh penjual)

d. Melakukan pengaturan pengiriman barang (mengatur jasa pengiriman yang disediakan oleh sistem e-commerce marketplace, biasanya dilakukan oleh penjual)

e. Retur (proses garansi biasanya dilakukan dalam sistem e-commerce market place, tujuannya agar kepercayaan pelanggan dapat tercapai/terpenuhi)

2. Keuntungan dari e-commerce marketplace, ditinjau dari:

a. Perusahaan :

$>$ Memperluas jaringan pemasaran, baik secara nasional maupun internasional

Mempersingkat saluran distribusi pemasaran

$>$ Membantu perusahaan skala kecil (UMKM) agar dapat bersaing dengan perusahaan skala besar

b. Pelanggan :

$>$ Memberikan kemudahan pelanggan untuk memilih produk yang diinginkan

Memberikan informasi tentang produk secara detail dan cepat

$>$ Memberikan konsumen agar dapat berinteraksi dengan komunitas secara digital dan bertukar pendapat

c. Masyarakat :

> Memberikan kesempatan untuk berwirausaha / bekerja di rumah (UMKM)

$>$ Dapat memilah barang/produk sesuai dengan kualitas yang baik dan harga yang lebih murah

Memberikan kesempatan layanan bagi masayarakat yang tinggal di daerah pedesaan 
3. Kekurangan dari e-commerce marketplace, ditinjau dari :

a. Segi teknologi :

$>$ Belum adanya tentang standard baku mengenai mutu, keamanan dan handal.

Masalah bandwith (jaringan internet)

Terkadang ada kendala di waktu pemeliharaan web server

b. Segi non-teknologi :

$>$ Banyaknya pelanggan yang bertransaksi di luar sistem e-commerce marketplace

$>$ Banyaknya anggapan bahwa e-commerce marketplace tidak aman dan mahal

$>$ Banyaknya penjual nakal, yang menjual barang/produk yang palsu/kw

\section{DAFTAR PUSTAKA}

Berapa Pangsa Pasar E-Commerce Indonesia. (2017). https://databoks.katadata.co.id/datapublish/ 2017/10/13/berapa-pangsa-pasar-e-commerce-indonesia/), diakses 1 Maret 2019.

Dewanto, Wawan, et al. (2015).Manajemen Inovasi untuk usaha mikro, kecil dan menengah. Edisi pertama. Bandung: CV.Alfabeta.

Dewanto, Wawan, et al (2014). Manajemen Inovasi : Peluang sukses menghadapi perubahan. Edisi pertama. Yogyakarta: CV.Andi Offset.

Fauzi, A., Mas'ud, M. I. (2019). Proses Manufaktur pada Mesin Primer dan Sekunder CV. Karunia Menggunakan Metode Linier Programming. Journal Knowledge Industrial Engineering (JKIE), 6(2), 59-65. https://doi.org/10.35891/jkie.v6i2.2055

Ishkak, E. (2005). Peranan Informasi Bagi Kemajuan UMKM. Yogyakarta : Kedaulatan Rakyat.

Junaedi, D., Mas'ud, M. I. (2018). Penerapan Metode Forecasting dalam Perencanaan Produksi bakpia dengan Menggunakan Software POM Guna Memenuhi Permintaan Konsumen. Journal Knowledge Industrial Engineering (JKIE), 5(3), 121-128. https://doi.org/10.35891/jkie.v5i3.2042

Jumlah Pembeli Online Indonesia Capai 119 Persen dari Populasi. (2018). (http://ekonomi. kompas.com/read/2018/09/07/164100326/jumlah-pembeli-online-indonesia-capai-119persen-dari-populasi/), diakses 1 Maret 2019.

Kuncoro, M. (2000). Usaha Kecil di Indonesia : Profil, Masalah dan Strategi Pemberdayaan. Jurnal Ekonomi dan Kewirausahaan, 11(1), 22.

Laudon, K.C \& Traver,C.G (2014). E-commerce: Business, Technology, Society. 10 edition.(www.academia.edu), diakses pada 4 maret 2019.

Li, Peixin dan Xie,Wei (2012). A Strategic Framework For Determining E-Commerce Adoption. Journal of Technology Management in China, 7(1), 22-35. Emerald Group Publishing Limited.

Mas'ud, M. I. (2016). Pendekatan Rantai Markov Dalam Pemilihan Universitas Di Kabupaten Pasuruan. Journal Knowledge Industrial Engineering (JKIE), 4(1), 63-70

Panduan FGD E-Commerce Kemendes.(2019). (https://ditjenpdt.kemendessa.go.id), diakses 4 Maret 2019.

Saydam, Gouzali. (2005). Teknologi Telekomunikasi, edisi pertama.Bandung: CV.Alfabeta.

Simson,Mike dan Docherty, Antony J.(2004). E-commerce Adoption Support and Advice for UK SMEs. Journal of Small Business and Enterprise Development, 11(3),315-328. Emerald Group Publishing Limited.

Suyanto, M. (2005).Aplikasi IT untuk UMKM Menghadapi Persaingan Global. Yogyakarta: Kedaulatan Rakyat.

Turban, E. (2010). Information Technology for Management: Transforming Organizations in Digital Economy. New Jersey : John Wiley \& Son.

Undang-Undang Republik Indonesia Nomor 20 Tahun 2008 Tentang Usaha Mikro, Kecil, dan Menengah. (http://bi.go.id/), diakses pada 3 Maret 2019.

Wertz, B 7 Kingyens,A.T. (2013).A Guide to Marketplace.Versionone.(www.versionone.vc), diakses pada tanggal 3 Maret 2019. 
Zhang, Huilan \& Okroafo Sam C.(2014). An E-Commerce Key Success Factors Framework for Chinese SME Exporters.International Journal of Economics and Finance, 6(1).Canadian Center of Science and Education. 